\title{
RUPTURED POSTERIOR COMMUNICATING ARTERY ANEURYSM IN A PRIMIGRAVIDA
}

\author{
Santhosh Narayanan ${ }^{1}$, Danish Ekkalayil2 ${ }^{2}$ Faisal $^{3}$
}

${ }_{1}^{1}$ Senior Resident, Department of General Medicine, Government Medical College, Kozhikode, Kerala. ${ }^{2}$ Assistant Professor, Department of General Medicine, Government Medical College, Kozhikode, Kerala. ${ }_{3}^{3}$ Assistant Professor, Department of General Medicine, Government Medical College, Kozhikode, Kerala.

HOW TO CITE THIS ARTICLE: Narayanan S, Ekkalayil D, Faisal. Ruptured posterior communicating artery aneurysm in a primigravida. J. Evolution Med. Dent. Sci. 2018;7(21):2644-2645, DOI: 10.14260/jemds/2018/593

\section{PRESENTATION OF CASE}

A 20-year-old primigravida at 8 weeks of gestation presented to us with history of drooping of the right upper eyelid. It was associated with pain over the upper part of right side of face. She had history of headache and giddiness 2 days back which subsided. There was no history of seizures, altered sensorium, blurring/ loss of vision, diplopia or hearing loss. She neither had sensory deficits nor weakness. Examination revealed complete third nerve palsy on the right side (Picture 1) with complete ptosis and loss of pupillary reflexes (Picture 2). Rest of the cranial nerves were within normal limits. Sensorimotor system was normal.

\section{DIFFERENTIAL DIAGNOSIS}

Compressive vascular lesion (PCOM aneurysm) was the first diagnosis. Other differential diagnosis considered was orbital lesion at the superior orbital fissure or an orbital pseudotumour, but absence of involvement of other cranial nerves made it a less likely possibility. Pituitary mass with apoplexy was another possibility, albeit in the absence of other neurological and endocrinological symptoms.

\section{CLINICAL DIAGNOSIS}

Clinically, patient had right complete third nerve palsy with loss of pupillary reflexes. Lateral gaze was preserved. Posterior communicating artery aneurysm with compression of third nerve was the working clinical diagnosis. Headache was attributed to sentinel bleed before aneurysm rupture.

Clinical Course: Computed tomography of brain was done at the time of admission to rule out subarachnoid haemorrhage. It did not reveal any abnormality. Lumbar puncture yielded clear CSF fluid with normal opening pressure and normal CSF analysis. MRI of brain with MR angiogram of cerebral vessels was done, which revealed enhancement in the paracavernous region with suspicion of an aneurysm of posterior communicating artery. Digital subtraction angiography of carotid vessels showed a giant posterior communicating artery aneurysm of $4 \mathrm{~cm}$ size with impending rupture (Picture 3). 6 hours after the procedure, patient developed generalised tonic-clonic seizure followed by unconsciousness. GCS fell to 5/15. CT brain showed subarachnoid haemorrhage. She was taken up for neurosurgical intervention. Clipping of aneurysm was done.

'Financial or Other Competing Interest': None.

Submission 08-04-2018, Peer Review 06-05-2018,

Acceptance 12-05-2018, Published 21-05-2018.

Corresponding Author:

Santhosh Narayanan,

\#27/685, Kuthiravattom Post,

Kozhikode-673016, Kerala.

E-mail: drsanthosh4@gmail.com

DOI: $10.14260 /$ jemds/2018/593
Postoperatively, she was ventilated, and intensive care given. She developed respiratory infection and septicaemia but recovered. Her ptosis also improved after two months. Her pregnancy was terminated. Ultrasonography of abdomen done to rule out cystic involvement of other organs was within normal limits.

\section{DISCUSSION OF MANAGEMENT}

About $30 \%$ of posterior communicating artery (PCom) aneurysms are associated with an oculomotor paralysis. A posterior communicating aneurysm may give rise to few attacks of severe headache localised to the orbit or side of forehead before onset of subarachnoid haemorrhage. ${ }^{1}$ Delay in neurosurgical intervention increases risk of mortality and incomplete recovery of third nerve function. Even though patients with a PCOM aneurysm typically present with subarachnoid haemorrhage (SAH), they can also present with subdural haemorrhage or isolated oculomotor nerve palsy. ${ }^{2}$ SAH usually involves the basal cisterns, but sometimes causes lobar haemorrhages or even involves the Sylvian fissure. The sequence of oculomotor impairment typically involves pupillary dilation followed by ptosis and finally extra-ocular paralysis/ paresis. Few patients can have pupil sparing oculomotor palsy. ${ }^{3}$

The variations in the anatomy of PCOM has clinical and therapeutic implications. The size of the PCOM artery ranges from a small artery often not visualised on imaging to a large vessel nearing the size of the posterior cerebral artery. ${ }^{4}$ The direction of the dome of aneurysm has surgical significance. In cases where the fundus of the aneurysm points anterolaterally, the origin of the artery appears to be masked by the aneurysm. Aneurysms with a superolateral fundus causes subdural haematoma and those with a posterolateral fundus causes intraparenchymal haemorrhage. ${ }^{5}$

Surgical clipping of the aneurysm and endovascular coil embolisation are the two treatment modalities. 6 If neck of the aneurysm could be adequately exposed and if the surgery does not involve significant manipulation of fundus, a good surgical outcome usually ensues. In a study published by Wirth et al, PCOM aneurysms had the lowest operative morbidity compared to other intracranial aneurysms. Recent technological advancements with balloon-assisted embolisation have raised the number of aneurysms that are amenable to coil embolisation. ${ }^{7}$ This is particularly for PCOM aneurysm, as it lies along the first order intracranial artery. The major drawback of endovascular embolisation is the high recurrence rate. ${ }^{8}$ PCOM aneurysms may be difficult to coil in a ruptured setting without the assistance of a stent or balloon. ${ }^{9,10}$ Unfortunately, at present without a randomised blinded study, we cannot come to a concrete conclusion about the efficacy of one treatment over the other; however, both treatment modalities appear to offer a reasonable chance of recovery. 


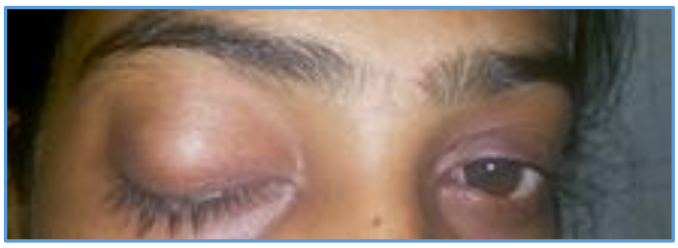

Picture 1. Right-Sided Complete Ptosis

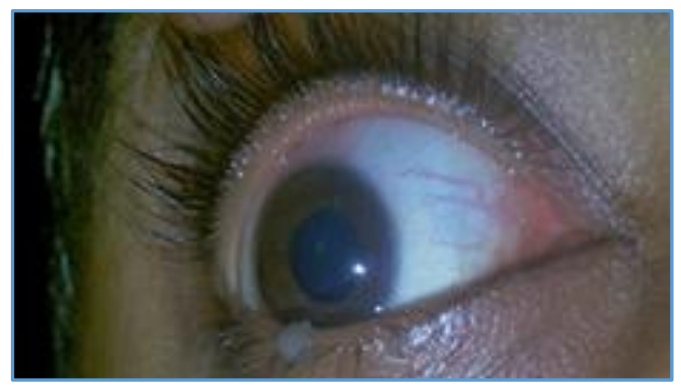

Picture 2. Dilated Pupil with Loss of Pupillary Reflex

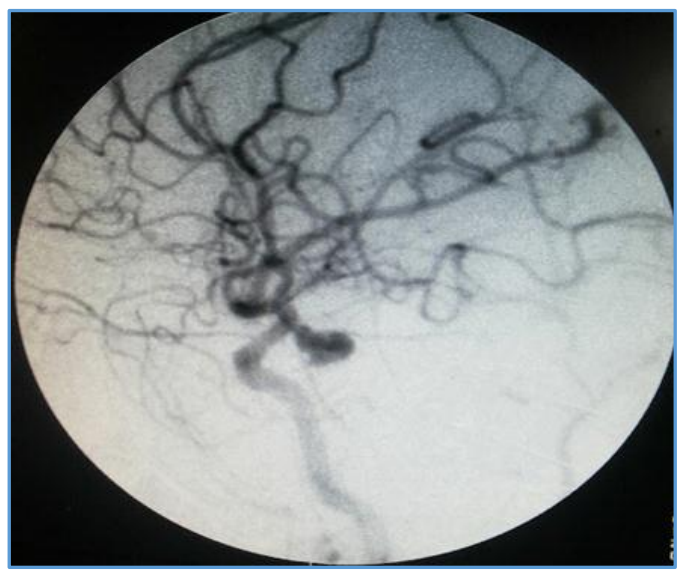

Picture 3. Digital Subtraction Angiography showing Large Posterior Communicating Artery Aneurysm

\section{FINAL DIAGNOSIS}

Posterior communicating artery aneurysm on the right side, complicated by subarachnoid haemorrhage due to rupture. Treated with surgical clipping of the aneurysm. Good clinical recovery on follow-up with mild residual oculomotor paresis.

\section{REFERENCES}

[1] Ahn JY, Han IB, Yoon PH, et al. Clipping vs coiling of posterior communicating artery aneurysms with third nerve palsy. Neurology 2006;66(1):121-3.

[2] Alexander TD, Macdonald RL, Weir B, et al. Intraoperative angiography in cerebral aneurysm surgery: a prospective study of 100 craniotomies. Neurosurgery 1996;39(1):10-7.

[3] Aikawa H, Kazekawa K, Nagata S, et al. Rebleeding after endovascular embolization of ruptured cerebral aneurysms. Neurol Med Chir 2007;47(10):439-45.

[4] Alshekhlee A, Mehta S, Edgell RC, et al. Hospital mortality and complications of electively clipped or coiled unruptured intracranial aneurysm. Stroke 2010;41(7):1471-6.

[5] Birchall D, Khangure MS, McAuliffe W. Resolution of third nerve paresis after endovascular management of aneurysms of the posterior communicating artery. AJNR Am J Neuroradiol 1999;20(3):411-3.

[6] Clarke G, Mendelow AD, Mitchell P. Predicting the risk of rupture of intracranial aneurysms based on anatomical location. Acta Neurochir 2005;147(3):25963.

[7] Bisaria KK. Anomalies of the posterior communicating artery and their potential clinical significance. J Neurosurg 1984;60(3):572-6.

[8] Campi A, Ramzi N, Molyneux AJ, et al. Retreatment of ruptured cerebral aneurysms in patients randomized by coiling or clipping in the international subarachnoid aneurysm trial (ISAT). Stroke 2007;38(5):1538-44.

[9] Botterell EH, Lloyd LA, Hoffman HJ. Oculomotor palsy due to supraclinoid internal carotid artery berry aneurysm. A long-term study of the results of surgical treatments on the recovery of third-nerve function. Am J Ophthalm 1962;54:609-16.

[10] Chen PR, Amin-Hanjani S, Albuquerque FC, et al. Outcome of oculomotor nerve palsy from posterior communicating artery aneurysms: comparison of clipping and coiling. Neurosurgery 2006;58(6):10406. 